\title{
Morphometric analysis of the drainage network in the Vitosha Mountain (preliminary results)
}

\section{Морфометричен анализ на речната мрежа във Витоша (предварителни резултати)}

\section{Petko Bozhkov \\ Петко Божков}

Sofia University “St. Kliment Ohridski”, Faculty of Geology and Geography, Department of Landscape Ecology and Environmental Protection, 15 Tsar Osvoboditel Blvd., 1504 Sofia; E-mail: petko_bozhkov@abv.bg

\begin{abstract}
The aim of the following case study is to analyze quantitatively the drainage network in the Vitosha Mountain, SW Bulgaria. Drainage network is outlined from topographic maps and extracted from digital elevation model (DEM). Several morphometric parameters are calculated - drainage density, channel-segment frequency, total stream length, etc. Hierarchy of tributaries and main rivers is also discussed.
\end{abstract}

Keywords: stream order analysis, linear parameters, drainage network, Vitosha.

Настоящото изследване засяга структурата на речната мрежа и ембрионалните ерозионни форми (бразди, ровини и оврази), развиващи се върху склоновете на планината Витоша. Избраната територия е много добре проучена в геоложко, геоморфоложко и физикогеографско отношение. Най-голям принос за изучеността на долинната мрежа на планината има Konstantinov (1987), който обрьща специално внимание на речната мрежа и връзката ѝ с издигането на планинската морфоструктура. Единствената карта на поредността на долините (Konstantinov, 1987) е изработена въз основа на едромащабни топографски карти, от които са изчертани единствено талвезите с постоянен отток. Отделни флувиални форми са описани от Georgiev (1965), Glovnya (1959), Hristov (1958), Petrov (1967) и Konstantinov \& Karabski (1986). Следователно ерозионната мрежа на Витоша, представена от ровини и овражни системи, остава практически неизследвана. Поради това създаването на точна карта на поредността на ерозионните форми е необходимо условие за провеждането на морфометричен анализ.

Границите на изследваната територия са определени от Petrov (1967), който отделя пла- нинските склонове от подножията като форма от оградните котловини - Софийска, Пернишка и Самоковска. В тези граници планината заема площ от 269,17 km². Най-големи по площ са водосборите на реките Боянска, Янчовска, Бистришка, Селска (Железнишка), Палакария, Струма, Мътница и Владайска.

За извършването на морфометричен анализ са използвани дигитализирани и геореферирани топографски карти в мащаб 1:50 000. Всички ерозионни форми с временен и постоянен отток са дигитализирани ръчно в ГИС (ESRI ArcMap 10.1), като данните са в проекция UTM Zone 34N (EPSG 32634). Създадена е база данни на поредността на речната мрежа и дължината на всеки един приток (табл. 1). Речната мрежа е генерирана от цифров модел на релефа (ЦМР) с пространствена резолюция 30 х 30 m по метода на Tarboton et al. (1991), с цел сравнение и верификация на получените резултати. За класифицирането на притоците е използвана дихотомическа система, разработена от Strahler (1952). Изчислени са основни морфометрични параметри като дължина на речната мрежа, средна дължина на потоците от дадена поредност (ранг), гъстота на речната мрежа и честота на потоците 

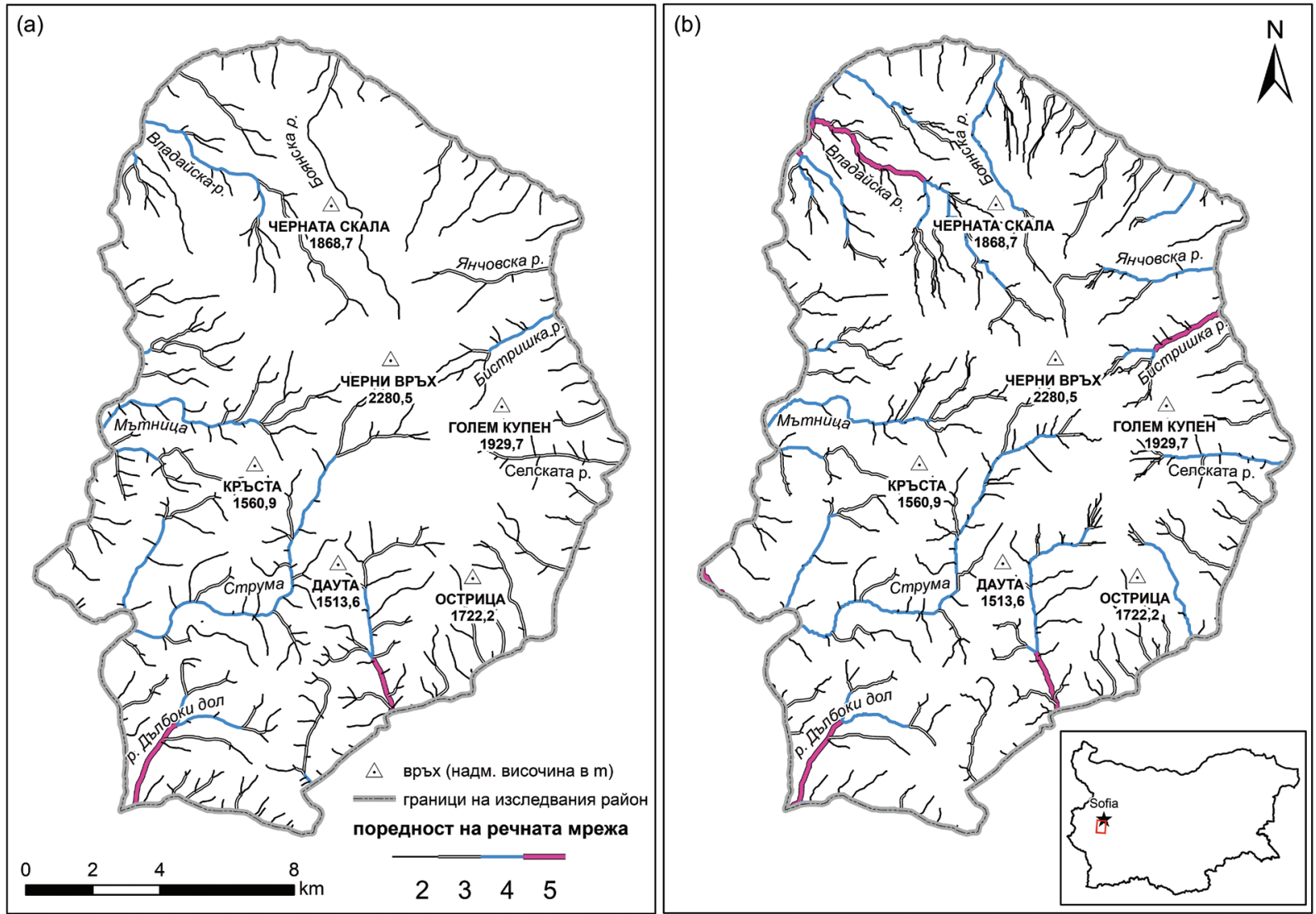

Фиг. 1. Поредност на речната мрежа във Витоша: а - резултати, получени чрез изчертаване на долините от топографски карти, $\mathrm{b}$ - резултати, генерирани от анализ на ЦМР

(Horton, 1932, 1945). Основните резултати от изследването са представени под формата на карти (фиг. 1).

Речната мрежа на Витоша включва 2033 потока от различна поредност, от които 1637 (табл. 1) или $80,5 \%$ от общия брой притоци представляват ровини без притоци и без постоянен воден поток. Те отвеждат води от валежи и снеготопене към по-нискоразположените притоци от втора поредност, в които се формира сезонен или постоянен отток. Поради големия си брой, притоците от първи ранг имат най-голяма обща дължина (табл. 1), но същевременно с това средната им дължина е най-малка. Притоците от втори ранг са около пет пъти по-малко на брой спрямо ерозионните форми от първа поредност. Те формират 15,4\% от общия брой притоци като общата им дължина намалява значително спрямо притоците от първи ранг (табл. 1). Долините от трета, четвърта и пета поредност са общо 82 , като средната им дължина надвишава $1 \mathrm{~km}$ (табл. 1). Общата дължина на речната мрежа на Витоша е 991,191 km, а гъстотата на речноерозионната мрежа е $3,68 \mathrm{~km} / \mathrm{km}^{2}$. Тази висока

Таблица 1. Основни характеристики на речна мрежа на Витоша

\begin{tabular}{cccccc}
\hline Поредност & $\begin{array}{c}\text { Брой } \\
\text { притоци }\end{array}$ & $\begin{array}{c}\text { Обща } \\
\text { дължина } \\
(\mathrm{km})\end{array}$ & $\begin{array}{c}\text { Максимална } \\
\text { дължина } \\
(\mathrm{km})\end{array}$ & $\begin{array}{c}\text { Минимална } \\
\text { дължина } \\
(\mathrm{km})\end{array}$ & $\begin{array}{c}\text { Средна } \\
\text { дължина } \\
(\mathrm{km})\end{array}$ \\
\hline 1 & 1637 & 650,963 & 1,910 & 0,051 & 0,398 \\
2 & 314 & 215,220 & 8,297 & 0,066 & 0,685 \\
3 & 67 & 84,141 & 4,863 & 0,173 & 1,256 \\
4 & 13 & 36,326 & 10,444 & 0,298 & 2,794 \\
5 & 2 & 4,540 & 2,816 & 1,724 & 2,270 \\
\hline
\end{tabular}


стойност се обяснява с наличието на множество притоци от първи ранг. По сьщата причина честотата на потоците е 7,55 бp/ $\mathrm{km}^{2}$.

Плановият рисунък на речната мрежа във Витоша е представен на фиг. 1. Според Konstantinov (1987) единствената река от пета поредност в изследвания район е Владайска река. Анализът на получените резултати от автоматизирания анализ на ЦМР в ГИС и от ръчното изчертаване на речно-ерозионната мрежа показва, че реките Дълбоки дол и Палакарийска (фиг. 1) също са от пети ранг като нарастването на поредността им се извършва на сравнително късо разстояние. Прави впечатление, че след цифровизиране на речната мрежа от топографски карти р. Владайска следва да бъде от четвърта поредност (фиг. 1a), докато анализът на ЦМР в ГИС (фиг. 1b) потвърждава получените от Konstantinov (1987) данни. Подобни разлики са видими и в йерархичния строеж на речната система на р. Боянска. Независимо от използвания метод за изчертаване на долинната мрежа, Бистришка река е от повисок ранг спрямо резултатите, представени от Konstantinov (1987).

Флувиалните форми и процеси имат водещо значение за развитието, функционирането и еволюцията на водосборните басейни. Получените морфометрични данни следва да бъдат анализирани на ниво водосборни басейни, с цел изследване на пространствените различия на речните системи. Подобни различия следва да се свържат с морфотектонското развитие на района, климатичните условия, залесеността и други физикогеографски характеристики на водосборите. Речната мрежа на Витоша е от радиално-центробежен тип, за което свидетелства плановият ѝ рисунък. В резултат на извършените анализи се установиха няколко различия в йерархичния строеж на речната мрежа от извършени предходни изследвания. Главната причина за нееднаквите резултати е различния мащаб на използвания изходен картен материал и геопространствените данни. Генерираните данни за речната мрежа от ЦМР имат редица предимства, сред които на първо място се нарежда краткото време за получаването им. Ocновният недостатък на тази техника се свързва с пространствената резолюция на ЦМР, от която зависи качеството на получените резултати. Изчертаването на речната мрежа от топографски карти е времеемък процес който се свързва с многократна проверка на генерираните данни. По-детайлни изследвания на ниво водосборни басейни, предмет на последващи изследвания, ще предоставят важни данни за риска от екстремни хидроложки и геоморфоложки процеси и явление във Витоша.

Благодарности: Публикацията е част от дейността по проект със заглавие „Морфометричен анализ на водосборни басейни във Витоша“, финансиран от Национална научна програма на $\mathrm{MOH} \mathrm{„Млади} \mathrm{учени} \mathrm{и} \mathrm{постдокторанти“} \mathrm{за} 2021$ г.

\section{Литература \\ References}

Georgiev, M. 1965. Géomorphologie du versant nord et nordouest de la montagne Vitocha. - Ann. Univ. Sofia, 58, 2géograph., 13-51 (in Bulgarian with French abstract).

Glovnya, M. 1959. Sur le relief périglaciaire en Bulgarie. Bull. Soc. Bulg. Géograph., 12, 15-23 (in Bulgarian with French abstract)

Horton, R. E. 1932. Drainage basin characteristics. - Eos, Transact. Amrican Geophys. Union, 13, 1, 350-361; https:// doi.org/10.1029/TR013i001p00350.

Horton, R. E. 1945. Erosional development of streams and their drainage basins; hydrophysical approach to quantitative morphology. - Bull. Geol. Soc. Amer., 56, 3, 275-370; https:// doi.org/10.1130/0016-7606(1945)56[275:EDOSAT] 2.0.CO;2.

Hristov, R. 1958. Recherches géologiques et géomorphologiques de Vitosha. - Ann. Inst. Mines et Géol., 5, 2-géol., 225-259 (in Bulgarian with French abstract).

Konstantinov, H. 1987. Caractéristique structure-morphométrique de Vitoša. - Ann. Univ. Sofia, 77, 2-géograph., 131146 (in Bulgarian with French abstract).

Konstantinov, H., B. Karabski. 1986. Geomorphological analysis of the isodeffic map of Vitosha. - Ann. Univ. Sofia, 76, 2-géograph., 17-27 (in Bulgarian with English abstract).

Petrov, P. 1967. A propos de quelques données morphométriques de Vitocha et de leur importance géomorphologique. - Ann. Univ. Sofia, 60, 2-géol., 51-71 (in Bulgarian with French abstract).

Strahler, A. N. 1952. Hypsometric (area altitude) analysis of erosional topology. - Bull. Geol. Soc. Amer., 63, 1117-1142; https://doi.org/10.1130/0016-7606(1952)63[1117:HAAOE $\mathrm{T}] 2.0 . \mathrm{CO} ; 2$.

Tarboton, D. G., R. L. Bras, I. Rodriguez-Iturbe. 1991. On the extraction of channel networks from digital elevation data. - Hydrol. Process., 5, 81-100; https://doi.org/10.1002/ hyp. 3360050107 . 